\title{
Performance of the $\mathrm{PA}_{\mathrm{X}}$ press $^{\mathrm{TM}}$ vs the ProSeal ${ }^{\mathrm{TM}}$ laryngeal mask airway during general anesthesia
}

\author{
[Efficacité du PA press $^{\mathrm{TM}}$ et du masque laryngé ProSeal ${ }^{\mathrm{TM}}$ durant l'anesthésie \\ générale]
}

Alexandre Lallo MD FRCPC, Pierre Drolet MD FRCPC, Mélanie Lacroix MD FRCPC

Purpose: The $\mathrm{PA}_{X}$ press $^{\mathrm{TM}}\left(\mathrm{PA}_{X}{ }^{\mathrm{TM}}\right)$ is a relatively new pharyngeal airway device that is easily inserted and effective in routine airway management. A prospective, randomized study was undertaken to compare the $\mathrm{PA}_{X}{ }^{\mathrm{TM}}$ with the ProSeal ${ }^{\mathrm{TM}}$ laryngeal mask airway $\left(P L M A^{T M}\right)$ during anesthesia with positive pressure ventilation.

Methods: One hundred adult patients scheduled for elective surgery under general anesthesia were randomized to airway management with either the $\mathrm{PA}_{X}{ }^{\mathrm{TM}}(n=50)$ or the $\mathrm{PLMA}^{\mathrm{TM}}(n$ $=50$ ). All patients swallowed a methylene blue capsule before anesthesia. After insertion, leak and inspiratory pressures were measured. Fibrescopy was used to view the glottis. Devices were inspected for blood or methylene blue staining upon removal at the end of surgery. An interview was conducted postoperatively to evaluate the occurrence of sore throat, dysphagia and dysphonia.

Results: Insertion time was longer for the $P A x^{T M}$ than for the $\mathrm{PLMA}^{\mathrm{TM}}(52 \pm 44 \mathrm{~s}$ vs $34 \pm 23 \mathrm{sec} ; P=0.003)$. Leak pressure was lower while peak inspiratory pressures, and $\mathrm{EtCO}_{2}$ values were higher $(P=0.016 ; 0.027$ and 0.04 respectively) with the $P A x^{T M}$. Both devices provided comparable fibreoptic viewing of the glottis. There were no differences with respect to the incidence or pattern of blue stains upon removal. Blood was seen more often on the $\mathrm{PAx}^{\mathrm{TM}}$ (58\% vs 19\%) and dysphagia was also more frequent and severe with the $\mathrm{PA}_{X}{ }^{\mathrm{TM}}$.

Conclusion: In comparison with the $\mathrm{PLMA}^{\mathrm{TM}}, \mathrm{PA}_{X}{ }^{\mathrm{TM}}$ insertion time is longer and the ventilatory characteristics of this new device may be marginally inferior. The $\mathrm{PA}_{X}{ }^{\mathrm{TM}}$ is also more traumatic and is associated with more postoperative discomfort compared to the PLMA ${ }^{\mathrm{TM}}$.

CAN J ANESTH $2007 / 54: 1 /$ pp 28-33
Objectif: Le PA ${ }_{X}$ press $^{\mathrm{TM}}\left(P A_{X}{ }^{\mathrm{TM}}\right)$ est un dispositif pharyngé de contrôle des voies aériennes relativement nouveau; il s'insère facilement et est efficace dans la pratique de tous les jours. Une étude prospective et randomisée a été entreprise afin de comparer le $P A_{X}{ }^{\mathrm{TM}}$ au masque laryngé ProSeal ${ }^{\mathrm{TM}}$ (PLMA ${ }^{\mathrm{TM}}$ ) pendant une anesthésie avec ventilation à pression positive.

Méthodes: Cent patients adultes devant subir une chirurgie élective sous anesthésie générale ont été randomisés à l'une de deux stratégies de gestion des voies aériennes: le $\mathrm{PA}_{X}{ }^{\mathrm{TM}}(n=$ 50) ou le PLMA ${ }^{\mathrm{TM}}(n=50)$. Tous les patients ont avalé une capsule de bleu de méthylène avant l'anesthésie. Après insertion, les pressions inspiratoires et de fuite ont été mesurées. Un fibroscope $a$ été utilisé pour visualiser la glotte. Les dispositifs ont été inspectés pour détecter des taches de sang ou de bleu de méthylène lorsqu'on les a retirés à la fin de la chirurgie. Une entrevue postopératoire a été menée afin d'évaluer l'incidence de maux de gorge, de dysphagie et de dysphonie.

Résultats : Le temps d'insertion a été plus long pour le Pax ${ }^{\top M}$ que pour le $P L M A^{T M}(52 \pm 44$ s vs $34 \pm 23$ sec; $P=0,003)$. Les pressions de fuite étaient plus faibles et les pressions inspiratoires maximum et les valeurs de $\mathrm{CO}_{2}$ expiré $\left(E t \mathrm{CO}_{2}\right)$ étaient plus élevées $\left(P=0,016 ; 0,027\right.$ et 0,04 respectivement) avec le $P A x^{\mathrm{TM}}$. Les deux appareils ont permis une visualisation comparable de la glotte par fibroscopie. II n'y a pas eu de différence au niveau de l'incidence ou de la présence de taches bleues lors du retrait des dispositifs. Du sang était cependant plus fréquemment observé sur le $P A x^{\mathrm{TM}}$ (58\% vs 19\%), de même qu'une dysphagie plus courante et sévère avec le $P A x^{\mathrm{TM}}$.

Conclusion : Comparé au PLMA ${ }^{\mathrm{TM}}$, le temps d'insertion du PAx ${ }^{\mathrm{TM}}$ est plus long et les caractéristiques de ventilation de ce nouveau dispositif sont légèrement inférieures. Le PAx ${ }^{\mathrm{TM}}$ est également plus traumatique et est associé à davantage d'inconfort postopératoire que le PLMA ${ }^{\mathrm{TM}}$.

From the Department of Anesthesiology, University of Montreal, Montreal, Quebec, Canada.

Address correspondence to: Dr. Alexandre Lallo, Department of Anesthesiology, CHUM, Hôpital Notre-Dame, 1560, Sherbrooke East, Montreal, Quebec H2L 4Ml, Canada. Phone: 514-890-8000, ext. 26876; Fax: 514-412-7653; E-mail: a.lallo@umontreal.ca

Funding: Airway devices were provided free of charge by Vitaid limited, Toronto ON, Canada (Proseal) and Trudell Medical Marketing

Limited, London ON, Canada $\left(\mathrm{PA}_{\mathrm{X}}\right.$ press).

Accepted for publication June 23, 2006.

Revision accepted October 10, 2006.

Competing interests: None declared. 


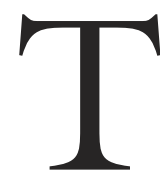

HE PA press $^{\mathrm{TM}}$ oropharyngeal airway $\left(\mathrm{PA}_{\mathrm{X}}{ }^{\mathrm{TM}}\right)$ (Figure 1 ) is a relatively new supraglottic airway device proposed as an alternative to other ventilatory tools such as the $\mathrm{LMA}^{\mathrm{TM}}$ and the COPA ${ }^{\mathrm{TM}}$. The anatomically curved tube of the $\mathrm{PA}_{\mathrm{X}}{ }^{\mathrm{TM}}$ comprises a circular, low pressure, oropharyngeal cuff intended to seal the airway while pushing the tongue slightly forward for improved ventilation. A flexible gilled tip is tapered to guide insertion and rest within the cricopharyngeal recess, above the esophageal sphincter. Ventilation occurs through an open hooded window on the anterior part of the tube, which aligns with the glottic opening. The $\mathrm{PA}_{\mathrm{X}}{ }^{\mathrm{TM}}$ can also be used for tracheal tube placement. It has been shown to be an easily inserted, effective airway device. ${ }^{1-3}$

The ProSeal ${ }^{\mathrm{TM}}\left(\mathrm{PLMA}^{\mathrm{TM}}\right)$ is a modified version of the classic LMA ${ }^{\mathrm{TM}}$ with a modified cuff to improve the seal and a drainage tube to isolate the glottis from the esophagus. ${ }^{4}$ Although its insertion has been shown to be longer and first time insertion success rates slightly lower, the PLMA ${ }^{\mathrm{TM}}$ provided higher airway sealing pressures when compared to the classic $\mathrm{LMA}^{\mathrm{TM} 5,6}$ without causing more sore throats or intraoperative complications.

The purpose of this prospective, randomized study was to compare the efficacy of the $\mathrm{PA}_{\mathrm{X}}{ }^{\mathrm{TM}}$ and the PLMA $^{\mathrm{TM}}$ with respect to oropharyngeal leak pressure and adequacy of ventilation during volume-controlled ventilation. As secondary outcomes we evaluated adequacy of positioning and the incidence of regurgitation based upon methylene blue stains on airway devices. The null hypothesis was that there would be no difference between devices with respect to oropharyngeal leak pressure.

\section{Methods}

After approval from our Institutional Review Board and obtaining written informed consent from each participant, 100 adult patients (ASA physical status I-III) undergoing general anesthesia for elective surgery were randomly assigned to have either a $\mathrm{PA}_{\mathrm{X}}{ }^{\mathrm{TM}}$ (Vital Signs Inc., NJ, USA) $(n=50)$ or a PLMA ${ }^{\mathrm{TM}}$ (The Laryngeal Mask Company, Henley-on-Thames, UK) $(n=50)$ for airway management. Randomizaion was done in blocks of ten patients and allocation concealment was achieved by drawing numbers from a sealed envelope. Excluded were patients with symptomatic gastroesophageal reflux/disease, a body mass index $>35 \mathrm{~kg} \cdot \mathrm{m}^{-2}$ and need for placement of a gastric tube. One operator (A.L.), experienced with both the PLMA $^{\mathrm{TM}}$ and the $\mathrm{PA}_{\mathrm{X}}{ }^{\mathrm{TM}}$, inserted all airway devices.

Each participant swallowed a gelatin capsule containing $50 \mathrm{mg}$ of methylene blue with $20-30 \mathrm{~mL}$ of

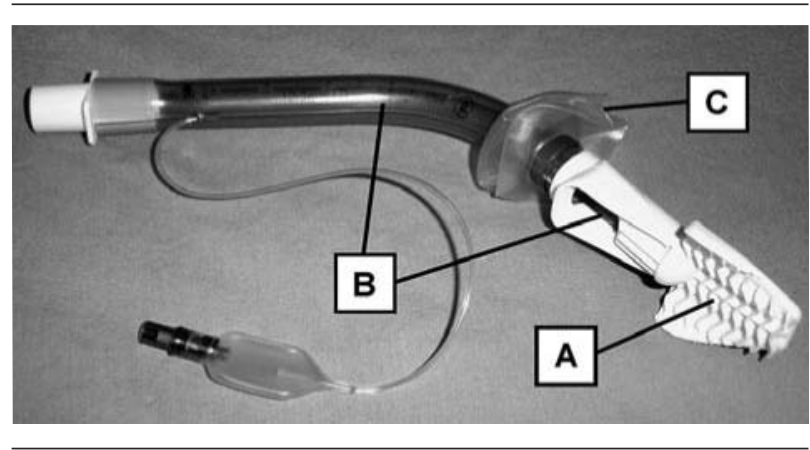

FIGURE 1 The $\mathrm{PA}_{\mathrm{X}}$ press $^{\mathrm{TM}}$ comprises A- flexible gilled tip designed to rest above the esophageal sphincter, B- ventilatory conduit ending with an open hooded window, C- circular low pressure oropharyngeal cuff intended to seal the airway.

water, ten to $15 \mathrm{~min}$ prior to the induction of anesthesia. Anesthetic management was standardized and routine monitoring was applied to all patients. After preoxygenation with $100 \% \mathrm{O}_{2}$ for three minutes, anesthesia was induced with fentanyl $\mathrm{l}-3 \mu \mathrm{g} \cdot \mathrm{kg}^{-1}$ iv and propofol $1.5-3.5 \mathrm{mg} \cdot \mathrm{kg}^{-1}$ iv. Muscle relaxation was achieved in all participants using rocuronium 0.6 $\mathrm{mg} \cdot \mathrm{kg}^{-1} i v$. Ventilation was provided via face mask with $100 \% \mathrm{O}_{2}$ until insertion of the selected airway device, two minutes after rocuronium injection. Either a $\mathrm{PA}_{\mathrm{X}}^{\mathrm{TM}}$ of universal adult size or a $\mathrm{PLMA}^{\mathrm{TM}}$ (size 4 for women and 5 for men) ${ }^{7}$ was used, according to group allocation. The $\mathrm{PA}_{\mathrm{X}}{ }^{\mathrm{TM}}$ was inserted according to the manufacturer's instruction manual. The cuff was first deflated and smoothed proximally. Lubricating jelly was then applied to the cuff and on both sides of the gilled tip. With the patient in a slight sniffing position, the $\mathrm{PA}_{\mathrm{X}}{ }^{\mathrm{TM}}$ was inserted in the mouth and the tip pushed backward and downward along the patient's midline, while maintaining contact with the hard palate, soft palate, and posterior pharyngeal wall until resistance was felt in the hypopharynx. The cuff was then inflated with $30 \mathrm{~mL}$ of air $(50 \%$ of the maximal recommended volume). If an audible leak was present when attempting manual ventilation, the cuff was further inflated in $10 \mathrm{~mL}$ increments (maximum $60 \mathrm{~mL}$ ) to obtain an effective seal. The PLMA ${ }^{\mathrm{TM}}$ was also inserted according to the manufacturer's instructions, without the introducer tool. It was first inflated at $50 \%$ of the maximal recommended cuff volume $\left(\mathrm{PLMA}^{\mathrm{TM}} 4 / 5: 15 / 20 \mathrm{~mL}\right.$ ) and volume was added in 5 -mL increments until no audible leak was heard and 
an effective airway was obtained (maximum volumes for $\mathrm{PLMA}^{\mathrm{TM}}$ 4/5: 30/40 mL). Three attempts were allowed for placement of each device and, if necessary, mask ventilation with sevoflurane $1-3 \%$ in oxygen was provided between attempts. A jaw-thrusting maneuver was used at the second attempt to aid placement and a laryngoscope was used for the third attempt. Three unsuccessful attempts were considered to be an insertion failure, after which an alternative airway device was used. The total time of placement, from insertion of the device in the mouth to the establishment of effective ventilation (no audible leak, symmetrical movement of the thorax and a square wave capnograph trace) was recorded. The number of attempts was also documented.

After confirming establishment of an effective airway, devices were connected to a circle breathing system and controlled ventilation (Ohio V5 ${ }^{\circledR}$ ventilator, Ohio medical products, Airco Inc., WI, USA) was adjusted to deliver $10 \mathrm{~mL} \cdot \mathrm{kg}^{-1}$ of body weight at a rate of 10 breaths. $\mathrm{min}^{-1}$ with an I:E ratio of $1: 2$. Spirometry and $\mathrm{EtCO}_{2}$ concentration were monitored (Capnomac Ultima, Datex-Ohmeda, Helsinki, Finland). After $30 \mathrm{sec}$ of stable ventilation with sevoflurane in oxygen, the oropharyngeal leak pressure was measured at $50 \%$ and $100 \%$ of the maximal recommended inflation cuff volume for each device. This measurement was achieved by closing the expiratory valve of the circle system at a fixed gas flow rate of $3 \mathrm{~L} \cdot \mathrm{min}^{-1}$ and noting the airway pressure (maximum $40 \mathrm{~cm} \mathrm{H}_{2} \mathrm{O}$ ) at which equilibrium was attained. ${ }^{8}$ Once the leak pressures were noted, a fibrescope was introduced just proximal to the end of the ventilatory conduit of each device, and the laryngeal view was graded using an established scoring system $(4=$ only vocal cords visible; $3=$ vocal cords and posterior epiglottis visible; 2 = vocal cords and anterior epiglottis visible; 1 = vocal cords not seen). ${ }^{9}$ Two minutes after fibrescopic visualization, the expired tidal volume, peak airway pressure, oxygen saturation and end-tidal carbon dioxide were recorded. The inspired oxygen fraction $\left(\mathrm{F}_{\mathrm{I}} \mathrm{O}_{2}\right)$ was then adjusted to keep $\mathrm{SpO}_{2}>95 \%$ (minimal $\left.\mathrm{F}_{\mathrm{I}} \mathrm{O}_{2}=0.3\right)$. Anesthesia was maintained with sevoflurane, fentanyl and rocuronium. Any intervention on the airway was also noted and graded as either minor (adjusting head/neck position, changing depth of insertion or adding air to the cuff) or major (requiring jaw thrust, reinsertion/change of device).

After completion of surgery and reversal of residual neuromuscular block, sevoflurane was discontinued and the airway device was removed from the patient's mouth upon awakening. Immediately after removal, the device was inspected for traces of blood or methy-
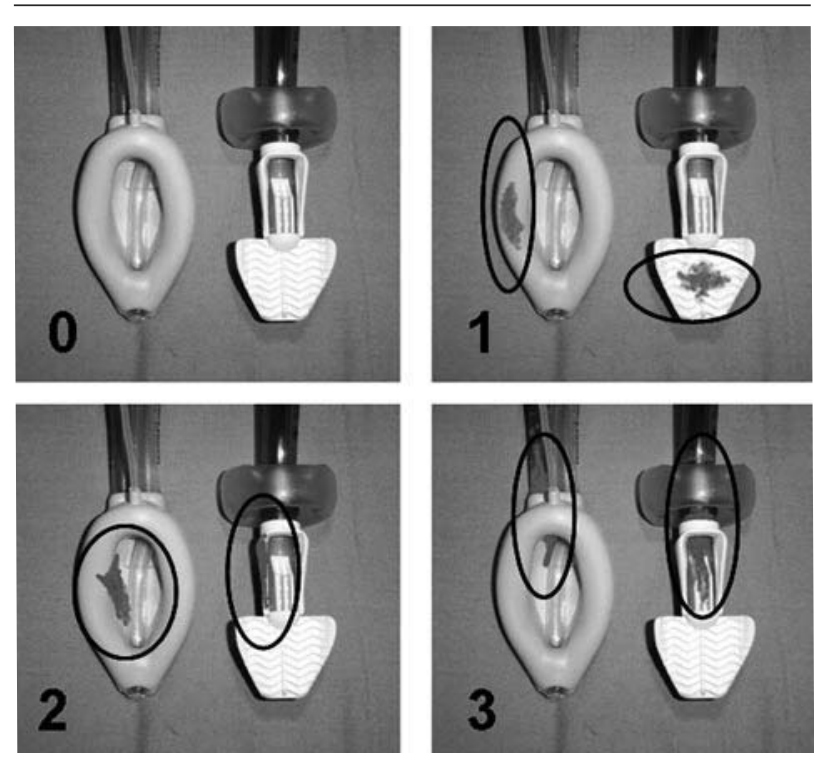

FIGURE 2 Graded methylene blue staining scale: 0- no visible stain, l- stains visible only on parts of the devices not directly in contact with the respiratory tract, 2- stains partly on parts of the devices in direct contact with the respiratory tract, 3 - stains entirely on parts of the devices in direct contact with the respiratory tract.

lene blue. Methylene blue staining was graded according to a scale previously described for the $\mathrm{LMA}^{10}$ and adapted to the $\mathrm{PA}_{\mathrm{X}}{ }^{\mathrm{TM}}$ (Figure 2). Additionally, a structured interview was conducted with the patients 18 to $24 \mathrm{hr}$ postoperatively. Patients were asked specifically about sore throat (pain independent of phonation or deglutition), dysphagia (difficulty or pain during swallowing), and dysphonia (pain on phonation/ altered voice). Each item was graded as absent, light, moderate or severe.

Sample size was determined based on a reported $\mathrm{SD}$ value of $6 \mathrm{~cm} \mathrm{H}_{2} \mathrm{O}$ for leak pressure. ${ }^{10}$ This protocol was designed to detect a 4-cm $\mathrm{H}_{2} \mathrm{O}$ difference in oropharyngeal leak pressure, accepting alpha and beta errors of 0.05 and 0.2 respectively. According to these parameters, a total of 36 patients per group were needed. Considering possible exclusions or failed attempts at positioning the devices, we decided to include 50 patients in each group. Student's $t$ test was used to compare continuous variables exhibiting normal distribution. Chi-square, Fisher's exact test and MannWhitney $\mathrm{U}$ test were used for non-continuous variables and continuous variables with non-normal distribution. $P$ values $<0.05$ were considered significant. 
TABLE I Demographic and surgical data

\begin{tabular}{lll}
\hline & $P A x^{\mathrm{TM}}(n=48)$ & $P L M A^{\mathrm{TM}}(n=48)$ \\
\hline Age $(\mathrm{yr})^{*}$ & $48 \pm 15$ & $48 \pm 14$ \\
Sex (male/female) & $10 / 40$ & $11 / 39$ \\
Weight $(\mathrm{kg})^{*}$ & $69 \pm 15$ & $70 \pm 15$ \\
Height $(\mathrm{m})^{*}$ & $1.65 \pm 0.10$ & $1.64 \pm 0.10$ \\
Body mass index & $25.2 \pm 4.5$ & $25.8 \pm 3.6$ \\
Position (supine/lithotomy) & $32 / 18$ & $30 / 20$ \\
Length of surgery (min)* & $75 \pm 36$ & $72 \pm 43$ \\
\hline
\end{tabular}

$\mathrm{PAx}^{\mathrm{TM}}=\mathrm{PA}_{\mathrm{x}}$ press $^{\mathrm{TM}} ; \mathrm{PLMA}^{\mathrm{TM}}=$ ProSeal $^{\mathrm{TM}}$ laryngeal mask airway.

${ }^{*}$ Mean \pm SD.

\section{Results}

A total of 100 patients were randomized, and 96 completed the protocol. Patient characteristics were similar in the two groups (Table I). There were no differences between groups with respect to the duration of surgery or the surgical positioning (supine/ lithotomy) of the participants.

There were two failures of insertion in each group (4\%) (Table II). Mean insertion times were longer $(52 \pm 44 \mathrm{sec})$ for the $\mathrm{PA}_{\mathrm{X}}{ }^{\mathrm{TM}}$ compared to the PLMA ${ }^{\mathrm{TM}}$ $(34 \pm 23 \mathrm{sec})(P=0.0003)$. The groups were similar with respect to first-time insertion success rates $(76 \%$ for $\mathrm{PA}_{\mathrm{X}}{ }^{\mathrm{TM}}$ vs $84 \%$ for the $\mathrm{PLMA}^{\mathrm{TM}}$ ). However, the oropharyngeal leak pressure at $50 \%$ of maximum cuff inflation was higher $(P=0.016)$ for the PLMA ${ }^{\mathrm{TM}}(22$ $\left.\pm 7 \mathrm{~cm} \mathrm{H} \mathrm{H}_{2} \mathrm{O}\right)$ compared to the $\mathrm{PA}_{\mathrm{X}}^{\mathrm{TM}}(18 \pm 8 \mathrm{~cm}$ $\mathrm{H}_{2} \mathrm{O}$ ), but there was no difference between groups when both cuffs were fully inflated. There was also no difference between groups with respect to the visualization scores of the cords. Peak airway pressure and
$\mathrm{EtCO}_{2}$, two minutes after fibrescopic examination, were greater in the $\mathrm{PA}_{\mathrm{X}}{ }^{\mathrm{TM}}$ group $\left(19 \pm 6 \mathrm{~cm} \mathrm{H}_{2} \mathrm{O}\right.$ and $33 \pm 4 \mathrm{mmHg}$ ) than in the PLMA ${ }^{\mathrm{TM}}$ group (16 $\pm 4 \mathrm{~cm} \mathrm{H}_{2} \mathrm{O}$ and $3 \mathrm{l} \pm 3 \mathrm{mmHg}$ ). Blood was seen more often, upon removal, on the $\mathrm{PA}_{\mathrm{X}}{ }^{\mathrm{TM}}$ than on the $\mathrm{PLMA}^{\mathrm{TM}}(58 \%$ vs $19 \%$ of patients, $P=0.0001)$. There was no difference with respect to the incidence or pattern of methylene blue staining on either device. The postoperative interview revealed that dysphagia was significantly more frequent in the $\mathrm{PA}_{\mathrm{X}}{ }^{\mathrm{TM}}$ group than in the PLMA ${ }^{\mathrm{TM}}$ group $(79 \%$ vs $50 \%$ of patients, $P=0.002)$. In all other respects, secondary outcome measures in the two groups were similar.

\section{Discussion}

Supraglottic devices are now an important part of airway management during anesthesia. Desirable characteristics for such devices include ease of insertion and minimal trauma. They should also act as effective conduits for controlled ventilation, while providing some degree of airway protection against regurgitated material arising from the gastrointestinal tract. Because the PLMA ${ }^{\mathrm{TM}}$ exhibits most of these characteristics to various degrees, the device is considered by many anesthesiologists to be the most appropriate supraglottic tool available for positive pressure ventilation. The $\mathrm{PA}_{\mathrm{X}}{ }^{\mathrm{TM}}$ is a new device that is designed to act as an effective ventilatory conduit while occluding the esophagus, thus providing some protection against gastroesophageal reflux. In spite of certain similarities with the PLMA ${ }^{\mathrm{TM}}$, there are some important differences which distinguish these devices. The $\mathrm{PA}_{\mathrm{X}}{ }^{\mathrm{TM}}$ is built to act as an effective conduit for passage of an endotracheal tube, but it does not provide a means for venting the oesophagus or insert a gastric tube. This

TABLE II Results: PAx ${ }^{\mathrm{TM}}$ ps PLMA $^{\mathrm{TM}}$

\begin{tabular}{|c|c|c|c|c|}
\hline & & $P A x^{\mathrm{TM}}(n=48)$ & $P L M A^{\mathrm{TM}}(n=48)$ & P value \\
\hline Insertion time $(\mathrm{sec})^{*}$ & & $52 \pm 44$ & $34 \pm 23$ & 0.0003 \\
\hline Attempts $(1 / 2 / 3 /$ Failure $)$ & & $38 / 8 / 2 / 2$ & $42 / 5 / 1 / 2$ & 0.747 \\
\hline \multicolumn{5}{|l|}{ Oropharyngeal leak pressure $\left(\mathrm{cm} \mathrm{H}_{2} \mathrm{O}\right)^{*}$} \\
\hline$-50 \%$ recommended cuff volume & & $18 \pm 8$ & $22 \pm 7$ & 0.016 \\
\hline - $100 \%$ recommended cuff volume & & $27 \pm 7$ & $30 \pm 7$ & 0.0946 \\
\hline Fibrescopic glottic view (grade $1 / 2 / 3 / 4$ ) & & $8 / 16 / 9 / 15$ & $4 / 10 / 19 / 15$ & 0.0983 \\
\hline Peak airway pressure $\left(\mathrm{cm} \mathrm{H}_{2} \mathrm{O}\right)^{*}$ & & $19 \pm 6$ & $16 \pm 4$ & 0.0268 \\
\hline $\mathrm{EtCO}_{2}(\mathrm{mmHg})^{*}$ & & $33 \pm 4$ & $31 \pm 3$ & 0.04 \\
\hline Blood on device (yes/no) & & $28 / 20$ & $9 / 39$ & 0.0001 \\
\hline Blue stain $($ grade $0 / 1 / 2 / 3) \dagger$ & & $41 / 2 / 1 / 4$ & $41 / 3 / 1 / 3$ & 0.951 \\
\hline \multirow[t]{2}{*}{ Interventions on the airway (none $/ 1 / 2 / 3 / 4)$} & Minor† & $37 / 9 / 0 / 1 / 1$ & $43 / 4 / 1 / 0 / 0$ & 0.255 \\
\hline & Major† & $43 / 5 / 0 / 0 / 0$ & $48 / 0 / 0 / 0 / 0$ & 0.056 \\
\hline \multirow[t]{3}{*}{ Postoperative interview (none/light/moderate/severe) } & Sore throat & $23 / 13 / 6 / 2$ & $35 / 7 / 4 / 2$ & 0.210 \\
\hline & Dysphagia & $10 / 13 / 15 / 6$ & $24 / 15 / 7 / 2$ & 0.002 \\
\hline & Dysphonia & $27 / 11 / 6 / 0$ & $33 / 12 / 2 / 1$ & 0.99 \\
\hline
\end{tabular}

$\mathrm{PAx}^{\mathrm{TM}}=\mathrm{PA}_{\mathrm{X}}$ press $^{\mathrm{TM}} ; \mathrm{PLMA}^{\mathrm{TM}}=$ ProSeal $^{\mathrm{TM}}$ laryngeal mask airway. ${ }^{*}$ Mean $\pm \mathrm{SD} ; \dagger$ See text for detailed description. 
study was conceived to compare characteristics that are common to both devices, and their effectiveness. That is why neither the possibility of intubating the trachea or inserting a gastric tube through the supraglottic airways was studied. These additional characteristics should be considered when selecting the most appropriate airway for a given patient.

This study suggests that, although the $\mathrm{PA}_{\mathrm{X}}{ }^{\mathrm{TM}}$ is a viable alternative for controlled ventilation during general anesthesia, it takes longer to insert, it provides slightly less effective ventilation, and it may be more traumatic in comparison to the PLMA ${ }^{\mathrm{TM}}$. Although the placement time of the $\mathrm{PA}_{\mathrm{X}}{ }^{\mathrm{TM}}$ was slightly longer in comparison to the $\mathrm{PLMA}^{\mathrm{TM}}$, the clinical importance of this modest difference needs to be considered on a case-by-case basis. It is important to note that in the majority of patients successful insertion was achieved on the first attempt. First attempt insertion rates observed for the PLMA ${ }^{\mathrm{TM}}$ (84\%) and the $\mathrm{PA}_{\mathrm{X}}{ }^{\mathrm{TM}}(76 \%)$ in our study are similar to observations from other studies. ${ }^{1,2,11-13}$ The failure rate was low (4\%) for both devices.

There was a slight difference in the airway sealing pressure between the two devices at $50 \%$ of the recommended maximal cuff volume, but no difference was observed when cuffs were inflated to their maximal recommended volumes. Given the different designs of the two devices, the clinical significance of variances in sealing pressures is uncertain, although in some circumstances the PLMA ${ }^{\mathrm{TM}}$ is likely to provide slightly higher sealing pressures than the $\mathrm{PA}_{\mathrm{X}}{ }^{\mathrm{TM}}$. The PLMA ${ }^{\mathrm{TM}}$ oropharyngeal leak pressure observed in this study was comparable to that found in other reports. ${ }^{6,11,14}$ Also, the peak airway pressure and $\mathrm{EtCO}_{2}$ values at standardized tidal volume were higher for the $\mathrm{PA}_{\mathrm{X}}{ }^{\mathrm{TM}}$ compared to the $\mathrm{PLMA}^{\mathrm{TM}}$. Although statistically significant, the clinical importance of these differences is likely to be modest. Still, cumulative findings suggest, again, that the PLMA ${ }^{\mathrm{TM}}$ may be a slightly more effective device from a ventilatory standpoint. The small differences in the ventilatory characteristics between both devices could not be explained by the fibrescopic observations, since both devices allowed comparable views of the cords and their surrounding structures.

The incidence and patterns of observed methylene blue stains upon removal of the studied devices were similar in the two groups. According to the scale used in this study, grade 2 and 3 patterns represented situations in which the observed staining was in direct contact with the glottis and the lower respiratory tract. Five patients in the $\mathrm{PA}_{\mathrm{X}}{ }^{\mathrm{TM}}$ group and four patients in the PLMA ${ }^{\mathrm{TM}}$ group exhibited such stain patterns. Although the clinical significance of these observa- tions is uncertain, these results suggest that both devices allowed for some material to migrate from the esophageal to the respiratory tract during the conduct of anesthesia. None of the nine patients with grade 2 or 3 stain patterns exhibited clinical signs of bronchial aspiration or pulmonary complications.

Blood was found three times more frequently upon removal of the $\mathrm{PA}_{\mathrm{X}}{ }^{\mathrm{TM}}$ compared to the PLMA ${ }^{\mathrm{TM}}$ (19\% vs $58 \%$ ). These results are in accordance with previous reports for both devices, $1,6,12$ and with other data showing higher hemodynamic changes upon insertion of the $\mathrm{PA}_{\mathrm{X}}{ }^{\mathrm{TM}}$ when compared to the Classic $\mathrm{LMA}^{\mathrm{TM}}{ }^{3}$ Such observations suggest that trauma is more likely to occur if the $\mathrm{PA}_{\mathrm{X}}{ }^{\mathrm{TM}}$ is used instead of the PLMA ${ }^{\mathrm{TM}}$. The tip of the $\mathrm{PA}_{\mathrm{X}}{ }^{\mathrm{TM}}$ used in this study was gilled on one side and smooth on the other (dorsal), as opposed to a previous model, which had gills on both sides. In spite of this modification, the incidence of trauma was still quite high in our study and in a majority of cases the blood was located, at least in part, on the gilled side of the tip. The more severe and more frequently observed dysphagia in the $\mathrm{PA}_{\mathrm{X}}{ }^{\mathrm{TM}}$ group suggests that this device is more traumatic compared to the PLMA $^{\mathrm{TM}}$.

This study protocol did not allow blinding of the operator inserting the airway devices. This is a source of potential systematic bias. Also, since the sample size was calculated using expected differences in oropharyngeal leak pressure, the study may be underpowered to demonstrate significant differences in some of the secondary endpoints, such as visualization of the glottis, incidence of regurgitation and dysphonia.

In conclusion, the PAx ${ }^{\mathrm{TM}}$ is an effective supraglottic airway device for positive pressure ventilation during routine surgery. However, in comparison to the PLMA ${ }^{\mathrm{TM}}$, it requires slightly more time to insert and it is associated with higher peak airway pressures and end-tidal $\mathrm{CO}_{2}$ values. The $\mathrm{PAx}^{\mathrm{TM}}$ is also more traumatic and is associated with more postoperative discomfort compared to the PLMA ${ }^{\mathrm{TM}}$.

\section{References}

1 Dimitriou V, Voyagis GS, Iatrou C, Brimacombe J. The PAxpress is an effective ventilatory device but has an $18 \%$ failure rate for flexible lightwand-guided tracheal intubation in anesthetized paralyzed patients. Can J Anesth 2003; 50: 495-500.

2 Dimitriou V, Voyagis GS, Iatrou C, Brimacombe J. A comparison of the PAxpress and face mask plus Guedel airway by inexperienced personnel after mannequinonly training. Anesth Analg 2003; 96: 1214-7.

3 Casati A, Vinciguerra F, Spreafico E, et al. Cardiovascular changes after extraglottic airway inser- 
tion: a prospective, randomized comparison between the laryngeal mask or the new PAXpress. J Clin Anesth 2004; 16: 342-6.

4 Brain AI, Verghese C, Strube PJ. The LMA 'ProSeal'--a laryngeal mask with an oesophageal vent. Br J Anaesth 2000; 84: 650-4.

5 Keller C, Brimacombe J. Mucosal pressure and oropharyngeal leak pressure with the ProSeal versus laryngeal mask airway in anaesthetized paralysed patients. $\mathrm{Br} \mathrm{J}$ Anaesth 2000; 85: 262-6.

6 Brimacombe J, Keller C, Fullekrug B, et al. A multicenter study comparing the ProSeal and Classic laryngeal mask airway in anesthetized, nonparalyzed patients. Anesthesiology 2002; 96: 289-95.

7 Kibara S, Brimacombe J. Sex-based ProSeal laryngeal mask airway size selection: a randomized crossover study of anesthetized, paralyzed male and female adult patients. Anesth Analg 2003; 97: 280-4.

8 Keller C, Brimacombe JR, Keller K, Morris R. Comparison of four methods for assessing airway sealing pressure with the laryngeal mask airway in adult patients. Br J Anaesth 1999; 82: 286-7.

9 Brimacombe J, Berry A. A proposed fiber-optic scoring system to standardize the assessment of laryngeal mask airway position. Anesth Analg 1993; 76: 457.

10 Abmed MZ, Vohra A. The reinforced laryngeal mask airway (RLMA) protects the airway in patients undergoing nasal surgery--an observational study of 200 patients. Can J Anesth 2002; 49: 863-6.

11 Cook TM, Nolan JP, Verghese C, et al. Randomized crossover comparison of the proseal with the classic laryngeal mask airway in unparalysed anaesthetized patients. Br J Anaesth 2002; 88: 527-33.

12 Lu PP, Brimacombe J, Yang C, Shyr M. ProSeal versus the Classic laryngeal mask airway for positive pressure ventilation during laparoscopic cholecystectomy. $\mathrm{Br} \mathrm{J}$ Anaesth 2002; 88: 824-7.

13 Abmed SM, Maroof M, Khan RM, Singhal V, Rizvi $K A$. A comparison of the laryngeal mask airway and $\mathrm{PA}$ (Xpress) for short surgical procedures. Anaesthesia 2003; 58: 42-4.

14 Evans NR, Gardner SV, James MF, et al. The proseal laryngeal mask: results of a descriptive trial with experience of 300 cases. Br J Anaesth 2002; 88: 534-9. 